J. Neurol. Neurosurg. Psychiat., 1958, 21, 95.

\title{
RECURRENT MULTIPLE CRANIAL NERVE PALSIES
}

\author{
BY \\ SIR CHARLES SYMONDS
}

London

The material for this paper comprises four case reports, which must necessarily be presented in some detail, having regard to the points in which they resemble and differ from one another. The resemblance between these cases is close enough to suggest that they constitute a recognizable clinical syndrome. As to their aetiology, the data permit no definite conclusion but suggest the possibility of a hypersensitivity reaction as a common factor.

\section{Case Reports}

Case 1.-Mr. S., aged 31, was first seen on June 29, 1951, complaining of headache and double vision.

There was no relevant family history. The past history revealed that while serving at sea in 1942 he had a facial paralysis of sudden onset, he could not recollect on which side. The onset was not accompanied by pain, paraesthesiae, or other symptoms. Recovery was complete in three weeks. In October, 1945, again while at sea, he noticed double vision. At this time he was sleeping badly and felt generally unwell, but not feverish. He was admitted to hospital at Haifa on October 10, 1945, and from the notes made at that time the following particulars are available. He complained of headache and slight pyrexia. There was paralysis of the right sixth cranial nerve. The cerebrospinal fluid was under a pressure of $190 \mathrm{~mm}$. It contained 2 lymphocytes per c.mm., $30 \mathrm{mg}$. per $100 \mathrm{ml}$. of protein, $740 \mathrm{mg}$. of chloride, and no excess of globulin. The Wassermann reaction was negative. The white blood count was 7,200 with a normal differential count. The Kahn reaction in the blood was negative. The ocular paralysis had recovered by October 16. He had a fortnight's convalescence and returned to full duty.

In March, 1946, he was demobilized A.1, but afterwards felt vaguely unwell and tired easily.

In April, 1948, for a period of 10 days he suffered from vertical headache, mainly at night. Some time later headache of a similar type recurred, and he became aware of difficulty in protruding his tongue to one side, he thought to the left. These symptoms soon subsided, but he then noticed a swelling in the right side of the neck. He was seen in Inverness by Mr. Hamilton, and a biopsy was carried out and an abscess drained. The diagnosis of tuberculous adenitis was made and confirmed histologically.

In July, 1950, he again experienced vertical headache, keeping him awake at night, and at the same time inability to protrude his tongue to the left with consequent dysarthria. These symptoms cleared up in 10 days. Early in 1951 discomfort and swelling appeared in the left testis, and he was seen by Mr. Hamilton, who diagnosed a tuberculous infection.

In April, 1951, he again suffered from headache, which began in the right parieto-temporal region and was severe, especially at night. Later the pain radiated into the right lower jaw and was also experienced in the left temple, radiating into the left lower jaw. This continued for a few weeks, when he suddenly noticed double vision, and the headache ceased. The images appeared side by side and were most separated when he looked to the left. Within two weeks the diplopia subsided but might recur occasionally when he was fatigued. Early in June he again complained of double vision with vertical displacement of the image, and slight left-sided ptosis. He was admitted to hospital, where the cervical adenitis and epididymitis were unchanged. Radiological examination showed no abnormality in the skull, and no evidence of active pulmonary disease. The blood showed $\mathrm{Hb} 91 \%$, white blood cells 7,200 per c.mm. with a normal differential count, and the blood sedimentation rate was $8 \mathrm{~mm}$. in the first hour. The urine contained no abnormal constituents and was sterile on culture. Lumbar puncture yielded a clear cerebrospinal fluid at a pressure of $105 \mathrm{~mm}$. of water with a prompt rise and fall on jugular compression. It contained 1 lymphocyte per c.mm., protein $30 \mathrm{mg}$., no excess of globulin, and chlorides $655 \mathrm{mg}$. per $100 \mathrm{ml}$. The colloidal gold curve showed no elevation.

Examination by the writer on June 29, 1951, revealed in addition to the right cervical adenitis and left epididymitis an incomplete left third nerve palsy. There was ptosis, with an enlarged pupil and weakness of all movements innervated by the nerve, especially elevation. No other abnormality was found in the examination of the nervous or other systems, but he looked ill. He returned home to remain under observation and early in July rather suddenly found difficulty in chewing, which he felt was due to weakness of the left jaw muscles. On palpation he discovered that the left masseter was not acting. This weakness, which was not accompanied by pain or paraesthesiae, disappeared in a few days. A week later he noticed in the morning a sense of dysequilibrium with a tendency to sway to either side. This worsened during the day and when he lay down he found that the slightest movement caused a sensation as of objects seen revolving. This was accompanied by vomiting. There was no 
tinnitus or deafness. For the next two days he experienced aggravation of the vertigo on turning his head to the left. He remained in bed $\mathbf{1 0}$ days, during which time the diplopia remaining from the third nerve lesion disappeared. Throughout the whole of this episode he had headache of the kind previously experienced from time to time during the course of his illness.

He was admitted to Guy's Hospital on August 15, 1951, when he had no symptoms other than general malaise. He was afebrile. No abnormality was to be found in the nervous system. In the neck a number of small, mobile, hard glands were present in the right posterior triangle, which to the feel were partly calcified. The left epididymis was enlarged, especially in its upper pole. He was examined by Dr. W. N. Mann, who confirmed these observations but could find no other abnormal physical signs. Radiographs of the skull showed no abnormality. Radiographs of the chest showed extensively calcified right cervical glands, but the lung fields were clear and the heart and hilar shadows normal. The cerebrospinal fluid was clear and colourless, with no cells, protein $30 \mathrm{mg}$. per $100 \mathrm{ml}$., no increase of globulin, and normal reduction of Fehling's solution. The Wassermann reaction was negative and the colloidal gold curve normal. The serum proteins were normal. No abnormal constituents were found in the urine, and the cultures were sterile. He was examined by Mr. F. R. Kilpatrick, who was of opinion that there had been a tuberculous focus in the left epididymis but that this organ was now practically normal. There was no clinical evidence of any active disease of the genito-urinary tract, and intravenous pyelograms were normal. A blood count on August 17 showed that the haemoglobin was $88 \%$ and the white cells numbered 6,000 , of which $70 \%$ were polymorphonuclear. The blood sedimentation rate was $10 \mathrm{~mm}$. in the first hour and $38 \mathrm{~mm}$. in two hours. Dr. Mann thereafter took charge of the patient, and I am indebted to him for the subsequent history.

Treatment was begun with intramuscular streptomycin and $p$-amino-salicylic acid (P.A.S.) on September 4 and continued for a period of six weeks. The blood sedimentation rates during this period were as follows:-

\begin{tabular}{lr|r|c}
\hline & 1 Hour & 2 Hours \\
\cline { 2 - 3 } Sept. & 4 & $17 \mathrm{~mm}$. & $39 \mathrm{~mm}$. \\
Sept. 17 & $15 \mathrm{~mm}$. & $37 \mathrm{~mm}$. \\
Oct. & 3 & $9 \mathrm{~mm}$. & $23 \mathrm{~mm}$. \\
Oct. & 10 & $7 \mathrm{~mm}$. & $19 \mathrm{~mm}$. \\
Oct. 16 & $8 \mathrm{~mm}$. & $19 \mathrm{~mm}$. \\
\hline
\end{tabular}

When examined by the writer on October 6 he felt mentally more alert and vigorous. He had had no return of headache. Until the end of September he had had occasional diplopia in the early morning but this had not occurred for a week. On examination the only abnormality found in the nervous system was that the left pupil was larger than the right. He was discharged from hospital on October 18 and advised to take three months of graduated convalescence. He was thereafter seen by Dr. Mann on February 4, 1952. He then stated that he felt extremely well and had no complaints at all. No new physical signs were found. Radiographs of the chest showed no abnormality. The blood sedimentation rate was $2 \mathrm{~mm}$. in the first hour and $6 \mathrm{~mm}$. in the second.

He remained well until July, 1953, when glands in the right side of the neck rapidly enlarged. After two weeks the swelling began to subside. At this juncture it is reported that the blood sedimentation rate and radiographs of the chest were normal. He was seen by Dr. Mann on July 23, who observed the right cervical glands to be larger than before, but advised that as he was now improving no further antibiotic treatment should be given at the moment.

In October, 1953, the patient complained of general malaise with slowness of thought and difficulty in concentration. He was re-admitted to Guy's Hospital under the care of Dr. Mann on November 15, 1953. Dr. Mann found fresh enlargement of the left epididymis, and possibly some extension of the enlarged right cervical glands. The blood sedimentation rate was $13 \mathrm{~mm}$. in the first hour. Radiographs of the chest showed no disease of the lungs. No neurological symptoms or signs had recurred. He was treated with streptomycin, 1g. daily, which was changed to $1 \mathrm{~g}$. thrice weekly together with isoniazid, $300 \mathrm{mg}$. daily. This treatment was continued for a month, during which he showed rapid clinical improvement, especially in his mental state. The blood sedimentation rate on December 9 was $11 \mathrm{~mm}$. in the first hour and $30 \mathrm{~mm}$. in the second. On December 21 he developed a swelling in the upper pole of the righto epididymis and was seen by Mr. Kilpatrick, who carried out a right epididymectomy on January 13, 1954. Histological examination confirmed the tuberculous nature of the lesion. Treatment with streptomycin and isoniazid was continued. Dr. Mann, in consultation with Sir Geoffrey Marshall, advised that the patient be transferred to the King Edward VII Sanatorium at Midhurst, where he was admitted on March 3, 1954, and discharged on September 1, 1954, having been given isoniazid and P.A.S. during the whole period of his stay. In November, 1954, the patient noticed enlargement of a gland in the right side of his neck and was again seen by Dr. Mann, who observed swelling of a gland adjacent to the group previously involved. This, however, was subsiding, and 14 days later was smaller. On January 25, 1955, it was no longer enlarged, the blood sedimentation rate was $11 \mathrm{~mm}$. in the first hour, and radiographs of the chest were again normal. He reported in October, 1957, that he was in good health and had remained so for over two years.

Case 2.-This patient was seen with Dr. Murray Baird at the Shaughnessy Hospital, Vancouver, B.C., in September, 1953. I am much indebted to him, and to the patient, who is herself a doctor, for providing me with the clinical and pathological data presented here.

Mrs. K. was aged 27 on her first admission to Shaughnessy Hospital on April 24, 1953.

In the family history the only observation of possible relevance was that a sister had tuberculous glands removed from her neck in childhood.

The patient between the ages of 16 and 19 was said to have had anaemia with low blood pressure and a liability to fainting attacks. During this period she had occasional attacks of what was called intercostal fibrositis. 
At the age of 17 she began to have occasional headache at intervals of three to six weeks.

In January, 1950, she had a right facial paralysis of rapid onset diagnosed at the time as a Bell's palsy. Recovery was virtually complete in three months. In June, 1951, there was a sudden onset of diplopia found to be caused by a right sixth nerve palsy, which cleared up in two weeks. In September, 1951, she had bilateral parotitis of 10 days' duration, diagnosed as mumps. During the six months before her admission she had two bouts of continuous headache lasting several days. A third bout had preceded her admission for a fortnight. It was described as continuous day and night, waking her at night, of fronto-occipital distribution and throbbing character, and increased by stooping, bowel movement, and coughing. On the day before admission she felt feverish and ill with nausea and aching in the jaws. On admission her temperature was $100^{\circ} \mathrm{F}$. but fell to normal two days later. No abnormal physical signs were found at this stage. On May 2 she developed right-sided headache with pain in and behind the right eye, and complained of diplopia, and in the course of the next two days developed an incomplete right third nerve palsy. At this stage she was examined by Dr. R. B. Kerr, who found the liver palpable at one inch below the costal margin and the spleen palpable at the costal margin. On May 6 lumbar puncture was done and a pressure of $165 \mathrm{~mm}$. recorded. The fluid was clear and contained 3 lymphocytes per c.mm. and $25 \mathrm{mg}$. per $100 \mathrm{ml}$. of protein.

Radiographs of the chest showed a small calcareous scar in the right mid lung field and a small calcified gland in the right hilar area. Radiographs of the skull, nasal sinuses, and teeth showed no abnormality. The blood sedimentation rate (Westergren) was 35 on admission and remained high throughout her stay in hospital, being 43 on May 19. The white and red blood counts and blood films showed no abnormality. The Paul-Bunnell test was negative as also was the agglutination test for Brucella abortus. No abnormality was found in the urine. The serum proteins were normal. During her stay in hospital her general symptoms improved, as also the third nerve palsy, but when discharged on May 20 she still had diplopia.

She was readmitted on June 3 with a two-day history of headache, vertigo, and vomiting. These symptoms subsided in the course of three days, leaving her for a further week with a liability to vertigo on quick movement of the head. On admission she was recorded to have a slight degree of right third nerve weakness. The liver and spleen were still palpable. She was afebrile, but the blood sedimentation rate was 47 . The blood count and films showed no abnormalities and the serum proteins were again normal. Radiographs of the chest showed no change and radiographs of the hands and feet showed no abnormalities. Two weeks after this second admission several subcutaneous nodules were observed on the legs. These are described by the patient as having been about the size of an almond and slightly tender, the overlying skin being red for the first 24 hours. Altogether about 14 nodules were noted. Two of these were removed for histological examination by Dr. M. V. Rae. They showed granulomatous tissue containing large numbers of multinucleated giant cells with no necrosis or caseation.

Dr. Rae's opinion was that the biopsy did not support the diagnosis of periarteritis nodosa, which had at one time been suggested. He thought the picture suggestive of Weber-Christian's panniculitis but that sarcoidosis was an alternative possibility.

Dr. Baird has kindly sent me sections of this material which have been submitted to Dr. Navasquez at Guy's Hospital. His opinion is that the morphology is consistent with either Boeck's sarcoidosis or non-caseating follicular tuberculosis.

The patient was discharged on July 22,1953 , and at that time still had diplopia and complained of headache when overtired or on straining. She tired easily, and her evening temperature was generally $99 \cdot 4^{\circ} \mathrm{F}$. She was then given a three-month course of treatment with streptomycin and P.A.S. (The exact dose has not been ascertained.) The blood sedimentation rates (Westergren) for the first hour during this period were as follows:

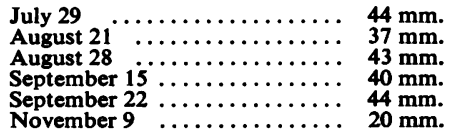

At the end of this treatment the diplopia had disappeared. She still, however, tired easily and had occasional headache, and the evening temperature ranged from $99^{\circ}$ to $100^{\circ} \mathrm{F}$. Thereafter her general condition improved and she became afebrile.

In April, 1954, she developed tenderness in the left lacrimal gland with sharp stabbing pain on lacrimation. This was followed by diminished tear production on that side. Shortly after this she went to Germany, her husband being in the Canadian Army. A month later she noticed wrinkling of the scleral epithelium just lateral to the iris of the left eye with smarting and a feeling as if a foreign body were present. She consulted an ophthalmic surgeon, who told her the trouble was due to a blocked lymphatic gland and prescribed cortisone ointment.

She subsequently reported in March, 1955, that she had had a child in the previous October, that her general health was good and that she had had no further symptoms of her old illness with the exception of two further subcutaneous nodules in the past few weeks.

Case 3.-Mrs. S., aged 57, was referred by Dr. Robinson, of Ackworth, on February 28, 1955, having recently recovered from an episode of double vision.

There was no relevant family history. In her childhood she had had enlarged glands in the left side of the neck for which an operation was performed. Otherwise she had had no illness until 1950 , when she felt generally ill and tired, and was said to have had some cardiac irregularity. From this she recovered with rest.

In January, 1951, she had a sudden onset of left facial paralysis without pain or paraesthesiae, and with no subjective involvement of taste. Recovery was virtually complete at the end of two weeks. Six weeks later she suddenly became aware of inability to protrude her tongue to the left. A left hypoglossal paralysis was confirmed by medical observation, and cleared up in a week. 
In August, 1952, she found one morning that her vision was blurred and by the evening had diplopia with vertical displacement of the images. With this there was no headache or other symptom. Six days later she was examined by Dr. Hugh Garland, who has kindly let me refer to his observations. At the time of this examination there was no diplopia but she tended to tilt her head backwards. No other abnormal physical signs were found. From the history Dr. Garland concluded that there had been a lesion of the right third nerve. She was admitted to hospital for investigation and the cerebrospinal fluid was found normal in every respect, the Wassermann reaction being negative in fluid and blood. At the end of two weeks from the onset she no longer experienced diplopia at any time and remained well until September, 1954, when she began to feel tired and wanting to rest. After a week or two she again experienced diplopia, which disappeared in a week. At the end of December a left facial weakness appeared, which lasted only for 48 hours. On January 6, 1955, she again experienced diplopia and was seen by Dr. Garland on January 12, who found that her vision was blurred on looking downwards and to the right only, though there was no obvious squint. He observed no other abnormal physical signs. On the suspicion that she might be suffering from myasthenia gravis he prescribed prostigmin, which she took up to $45 \mathrm{mg}$. thrice daily. As this caused colic she ceased taking it after a few days. She stated that the diplopia was already improving when she started the treatment and became no worse when she ceased taking the tablets. It lasted in all for about a fortnight. In the last week of January she developed herpes zoster in the distribution of the right second, third, and fourth lumbar dermatomes.

Examined by the writer on February 28 she appeared alert and well, and no abnormal physical signs were found except a slight left lower facial weakness, the scars of the recent herpetic eruption, and a scar in the left side of the neck resulting from the operation for cervical adenitis in childhood.

In view of the experience gained from Case 1 her doctor was advised to have the possibility of an active tuberculous infection investigated. She was then seen by Dr. J. J. Danaher, consultant to the Chest Clinic, Barnsley, who has kindly supplied the following data. No clinical evidence of active tuberculosis was discovered, but tuberculin sensitivity tests at that time, and when repeated after an interval of three months, showed: To O.T. 1 in 10,000 (Mantoux) a positive severe reaction, oedema $16 \mathrm{~mm}$.; erythema $22 \mathrm{~mm}$.; to the P.P.D. patch test, a positive reaction; severe vesication in both bovine and human elements.

His conclusion was that she was suffering from an active, but indolent, tuberculous infection of uncertain location. She was accordingly treated on his advice with bed rest and isoniazid in a daily dosage of $330 \mathrm{mg}$. for three months. Eighteen months after the completion of treatment she was reported to be in excellent health and in her own words "better than she had felt for years". The cranial nerve palsies had not recurred. At this time the sensitivity reaction to O.T. in a 1 in 10,000 dilution was minimal.
Case 4.-I am indebted to Dr. N. S. Alcock for the opportunity of seeing this patient and referring to his observations.

Mrs. M., a widow, aged 63 at the time of my examination in October, 1957, was then complaining of some difficulty in chewing and articulation.

In her family history the relevant facts were that her mother had suffered from asthma in her later years, and that her father had been subject to headaches like her own. She married at the age of 31 and had one child, who died of measles and pneumonia aged 7. She described herself as always nervous, but since childhood had had no particular illness until 1950. She then had a period of two to three weeks of more or less continuous mid-frontal headache and after this lost weight.

In March, 1951, similar headache recurred, she felt generally ill, and after two weeks experienced diplopia. She was subsequently seen at the National Hospital, Queen Square, by Dr. M. J. McArdle, who found paralysis of the left sixth nerve. The Wassermann reaction was negative in her blood. The haemoglobin was $100 \%$, and the white blood count 10,000 per c.mm. The E.S.R. was $14 \mathrm{~mm}$. in the first hour. The urine contained no albumin, sugar, or red cells. Radiographs of the skull, including the superior orbital fissures and optic foramina, were normal. Intermittent headache continued, but the diplopia improved and had disappeared by August. In November in the course of a week-end, during which she felt generally ill, she developed a left facial paralysis, from which recovery was complete in a month. At this time she began to have attacks of asthma. These attacks would last for an hour or so, and would occur in bouts with intervals of freedom. The liability to headache continued.

In May, 1953, she again felt generally ill and in the course of the next day or two developed diplopia, which proved due to a paralysis of the right sixth nerve. From this she recovered in three months. The asthma and headache continued, and in October of this year diplopia recurred with lateral separation of the images, but no observation is available as to which muscle was at fault. On this occasion the diplopia lasted six weeks, and there was another similar episode in August, 1954.

In February, 1956, she again had a left facial palsy of subacute onset, recovering in a month, and a further episode of diplopia in June lasting for four months. During the period 1955 to 1957 the attacks of asthma became progressively less frequent and severe, but intermittent headache continued, being now mainly in the left parietal region.

In April, 1957, she noticed difficulty in pronouncing sibilants and inability to pass food across her mouth, and when examined by Dr. Alcock was found to have paralysis of the right twelfth nerve. She was admitted to hospital under his care, where no signs of nervous disease were found other than the paralysis of the right side of the tongue. The E.S.R. was $5 \mathrm{~mm}$. in the first hour, and haemoglobin $112 \%$. The cerebrospinal fluid showed no cells, $60 \mathrm{mg}$. of protein, a negative Wassermann reaction, and a negative Lange curve. Subsequently radiographs of the skull and chest were normal.

At the time of my examination the hypoglossal palsy 
was nearly recovered, and the tongue showed no wasting or fibrillation. No other abnormal signs were found in the nervous system. The blood pressure was 170 and $85 \mathrm{~mm}$. $\mathrm{Hg}$. The retinal arteries were a little uneven in calibre. The pulses in both carotid, temporal, dorsalis pedis, and posterior tibial arteries were normal. It was some months since her last bout of asthma, and she stated that her headaches were becoming less frequent and severe.

\section{Discussion}

In each of the cases related there was a succession of cranial nerve palsies of rapid onset and transient duration, occurring at irregular, and sometimes long, intervals over a period of several years. For convenience of comparison the order and time intervals are summarized in Table $\mathbf{I}$.

It will be noted that with the exception of vertigo in Cases 1 and 2, assumed to be due to involvement of one of the vestibular nerves, the affection was confined to motor nerves. Common to all cases was involvement of the seventh nerve, and in all but Case 4 this was the first of the series of cranial nerve palsies. In Case 2 the cranial nerves affected were all on the same side with the possible exception of the vestibular lesion presumed to have caused the episode of vertigo. The site of the lesion causing vertigo in this case and in Case 1 cannot be determined as no caloric tests were done. In Cases 1 , 3 , and 4 at one time or another cranial nerves on either side were affected. There was no evidence in any case of involvement of the conducting tracts in the brain stem or of any other part of the nervous system. Headache was a prominent symptom in Cases 1, 2, and 4, but was absent in Case 3 . In Case 2 the aggravation by coughing and straining was suggestive of intracranial disease.

The cerebrospinal fluid in each case was normal in every respect, including a negative Wassermann reaction and normal colloidal gold curve.

From the neurological aspect these cases are like enough to one another and so different from any well recognized disease of the nervous system that they might be suspected on these grounds to have some common factor in their aetiology. That this was of a toxic or infective character appears probable, for in all four cases there were from time to time symptoms of constitutional disturbance. In Case 1 these symptoms were eventually proved to be due to a tuberculous infection of a particularly chronic kind, without pulmonary involvement, which eventually responded to antibiotic treatment. From the time this was begun there was no recurrence of the cranial nerve palsies, although evidence of active infection was still present three years later. During the subsequent three years, however, there has been no sign of further activity.

In Case 2 there was no evidence of active tuberculous infection. There were, however, several features suggestive of sarcoidosis. The appearance of subcutaneous nodules in this disease is recognized, and the biopsy findings in this case were consistent with the diagnosis. The enlargement at one time of the liver and spleen, and the later affection of a lacrimal gland, are also suggestive. So also is the chronic nature of the illness, fresh subcutaneous nodules being reported by the patient two years after her first admission to hospital for constitutional symptoms,

In Case 3 the only evidence for active tuberculous infection was that derived from skin sensitivity tests together with the diminished skin sensitivity and apparent clinical recovery after a course of treatment with isoniazid.

In Case 4 the earliest symptoms were headache and loss of weight, and the first episode of cranial nerve palsy and several subsequent episodes were preceded by a period of general malaise. Within a year of the first symptoms asthma developed and continued thereafter for five years.

Cranial nerve palsies are not known to occur in the course of tuberculous infection apart from tuberculous meningitis, and it is evident both from clinical observation and the examination of the cerebrospinal fluid in these cases that this cannot have been present.

Cranial nerve palsies, however, have been frequently reported in sarcoidosis (Colover, 1948; Jefferson, 1957). Any of the cranial nerves may be

TABLE I

ORDER AND TIME INTERVALS OF CRANIAL NERVE PALSIES IN PRESENT SERIES

\begin{tabular}{|c|c|c|c|c|c|c|c|}
\hline \multicolumn{2}{|c|}{ Case 1} & \multicolumn{2}{|c|}{ Case 2} & \multicolumn{2}{|c|}{ Case 3} & \multicolumn{2}{|c|}{ Case 4} \\
\hline $\begin{array}{l}\text { Cranial Nerve } \\
\text { Affected }\end{array}$ & Date & $\begin{array}{c}\text { Cranial Nerve } \\
\text { Affected }\end{array}$ & Date & $\begin{array}{c}\text { Cranial Nerve } \\
\text { Affected }\end{array}$ & Date & $\begin{array}{c}\text { Cranial Nerve } \\
\text { Affected }\end{array}$ & Date \\
\hline $\begin{array}{l}7 \text { ? R or L } \\
6 \stackrel{R}{\mathrm{R}} \\
12 ? \mathrm{~L} \\
12 \mathrm{~L} \\
6 \mathrm{~L} \\
3 \mathrm{~L} \\
5 \text { Motor L } \\
8 \text { Vestibular }\end{array}$ & $\begin{array}{l}1942 \text {, October } \\
\text { 1945, Octob } \\
\text { 1948, May } \\
\text { 1950, July } \\
\text { 1951, April } \\
\text { 1951, June } \\
\text { 1951, July } \\
\text { 1951, July }\end{array}$ & $\begin{array}{l}7 \mathrm{R} \\
6 \mathrm{R} \\
3 \mathrm{R} \\
8 \text { Vestibular }\end{array}$ & $\begin{array}{l}\text { 1950, January } \\
\text { 1951, June } \\
\text { 1953, April } \\
\text { 1953, June }\end{array}$ & $\begin{array}{rl}7 & \mathrm{~L} \\
12 \mathrm{~L} \\
3 \mathrm{R} \\
3 \text { (Probable) } \\
7 \mathrm{~L} \\
3 \text { (Probable) }\end{array}$ & $\begin{array}{l}\text { 1951, January } \\
\text { 1951, March } \\
\text { 1952, August } \\
\text { 1954, September } \\
\text { 1954, December } \\
\text { 1955, January }\end{array}$ & $\begin{array}{l}6 \mathrm{~L} \\
7 \mathrm{~L} \\
6 \mathrm{R} \\
\text { Diplopia } \\
\text { Diplopia } \\
7 \mathrm{~L} \\
\text { Diplopia } \\
12 \mathrm{R}\end{array}$ & $\begin{array}{l}\text { 1951, March } \\
\text { 1951, November } \\
\text { 1953, May } \\
\text { 1953, October } \\
\text { 1954, August } \\
\text { 1956, February } \\
\text { 1956, June } \\
\text { 1957, April }\end{array}$ \\
\hline
\end{tabular}


affected. The facial nerve is that most frequently involved, and this may occur in the absence of parotitis. These cranial nerve palsies are often transient. They are presumably due to sarcoid nodules involving the sheath of the nerve or neighbouring meninges. Meningeal involvement may cause headache, and sometimes obstructive hydrocephalus (Colover, 1948). Headache was a prominent symptom in Cases 1, 2, and 3 of the present paper, and in Case 2 was of hydrocephalic type. There is, however, no case known to the writer in which a history of recurrent, transient cranial nerve palsies over a period of several years has been recorded in association with an established diagnosis of sarcoidosis. Nor was there anything to support the diagnosis of sarcoidosis in the other cases recorded here.

The aetiology of sarcoidosis remains uncertain. Coope (1952), summarizing the evidence at that time, concluded that in most cases the sarcoid lesion was an atypical proliferative reaction to the tubercle bacillus or to some chemical constituent of that organism. Evidence in favour of Coope's hypothesis has been presented by Nethercott and Strawbridge (1956), who found in sarcoid lesions chemical substances which are believed to be derived from tubercle bacilli, concluding that these lesions had previously been tuberculous, though there was no clinical or bacteriological evidence of tuberculous infection. Yet the association of tuberculosis and sarcoidosis is inconstant, and it appears at present best to regard sarcoidosis as a disease only in the sense that it has recognizable clinical and histological features (Lancet, 1956) with the qualification that in some cases tuberculous infection may be a causal factor. Jefferson (1957) has lately reviewed the problem and inclines to the view that sarcoidosis is not an aetiologically pure condition but represents a non-specific tissue reaction of the hypersensitivity type.

To return to the cases presented in this paper, they appear to represent a homogeneous group within the syndrome of polyneuritis cranialis. In one instance the clinical diagnosis of sarcoidosis appears tenable, and in another active tuberculous infection was present. Of the two remaining cases, in one there was some evidence in favour of tuberculous infection, and in the other an association with asthma. It seems possible, therefore, that these recurrent cranial nerve palsies may represent a selective hypersensitivity reaction involving the connective tissue elements of the nerves or their meningeal coverings, which is not specific for any single cause. In this respect the syndrome would resemble sarcoidosis, in which disease transient 0 cranial nerve palsies are known to occur.

\section{REFERENCES}

Colover, J. (1948). Brain, 71, 451.

Coope, $\mathbf{R}$. (1952). In British Encyclopaedia of Medical Practice. 2nd ed., Vol. 11. Butterworth, London.

Jefferson, M. (1957). In Modern Trends in Neurology (2nd series) ed. D. Williams. Butterworth, London.

Lancet (1956). 2, 1339 (Leading Article).

Nethercott, S. E., and Strawbridge, W. G. (1956). Lancet, 2, 1132 